\title{
Esophagus: the effect of large doses of serotonin on motor function
}

\begin{abstract}
Background: Serotonin (5-hydroxytryptamine, 5-HT) is a regulatory and biologically active neurotransmitter and a hormone in the CNS and many organs, including the esophagus. It is known that serotonin as well as acetylcholine stimulates contractile activity of the esophageal smooth muscles. However, role of different serotonin receptors in realization of large doses of serotonin in contractile activity of the esophagus is insufficiently known.
\end{abstract}

Aim: To determine receptor mechanisms in realization of large doses of serotonin in contractile activity of the esophagus.

Subject and methods: This is an electromyography study of esophagus contractile activity of rat under a large serotonin doses stimulation of 5-HT3, 4 and 5-HT2, 1 receptors modulated separately. The role of different serotonin receptors in the 5-HT contractile activity of the esophagus was evaluated by measuring the amplitude and frequency of the slow wave and spices of electromyogram (EMG) by the noninvasive microelectrodes imposed on the adventitial layer of the esophagus.

Results: Administration of the 5-HT4 receptors inhibitors excluded large dose serotonin induced the increment of EMG activity of the contractile activity of the esophagus. Administration of the 5-HT3 receptors inhibitors not fully excluded large dose serotonin induced the increment of EMG activity of the contractile activity of the esophagus. Administration of the 5-HT1,2 receptors inhibitors blocked the serotonininduced increment of EMG activity of the contractile activity of the esophagus.

Conclusion: Our results indicate that serotonin plays an important role in the regulation of the rat's esophagus contractility. Influence of a large doses of 5-HT on contraction of the esophageal smooth muscles is inhibited by blockers of 5-HT1,2, 4 receptors but not fully excluded by blocker of 5-HT3-receptors.

Keywords: esophagus, contraction, large doses serotonin, serotonin receptors
Volume 10 Issue 2 - 2019

\author{
Lychkova AE,' Severin AE, ${ }^{2}$ Torshin VI, ${ }^{3}$ \\ Starshinov Yu P, Puzikov AM ${ }^{5}$ \\ 'Head of Division of the Moscow's Clinical Research Practical \\ Center, Moscow Health Department, Russia \\ ${ }^{2}$ Professor, Normal Physiology Department, Russian People's \\ Friendship University, Russia \\ ${ }^{3}$ Professor, Head of the Normal Physiology Department, Russian \\ People's Friendship University, Russia \\ ${ }^{4}$ Head of the Department of Ultrasonic Diagnostics, Moscow's \\ Clinical Research Practical Center, Moscow Health Department, \\ Russia \\ ${ }^{5}$ Researcher of the Division of the Moscow's Clinical Research \\ Center, Moscow Health Department, Russia
}

Correspondence: Lychkova Alla Edward, Head of Division of the Moscow's Clinical Research Center, Moscow Health Department, Moscow, Russia, Email lychkova@mail.ru

Received: January 31, 2018 | Published: March 21, 2019
Abbreviations:5-HT, serotonin; 5-HT1-, 5-HT2-, 5-HT3-, and 5-HT4, serotonin receptors; EMG, electromyogram

\section{Introduction}

The esophagus is a flattened muscular tube; the main functions of the esophagus are to transport food from the pharynx to the stomach and to prevent the reflux of gastric contents into the esophagus. The movement of the bolus along the esophagus is provided basically by the peristaltic movement of the muscular membrane of the esophagus, and also the sphincter. The mechanisms of peristalsis resides in the esophageal wall. ${ }^{1}$ The dominant cell population of the esophagus from that point of view is the muscle cells that contain the contractile apparatus responsible for the generation of the contractile force.

A strict regulation of contractility of the esophagus is essential to avoid gastroesophageal reflux and other dysfunctions of the upper digestive tract. The muscles of the esophagus are controlled by various neuronal, hormonal, metabolic, and mechanical factors, including intramural acetylcholine and serotonin (5-hydroxytryptamine, 5-HT). The esophagus is innervated by the vagus nerve, the cervical and thoracic sympathetic trunk, Auerbach's plexus in muscular layers, serotonergic fibres, and neurons. ${ }^{2}$

Serotoninergic system is formed by its bioamine, receptors, SERT transporter (monoamine transporter protein, which is formed by sodium-potassium transporter), enzyme of 5-tryptophan hydroxylase-1 and -2 synthesis and catabolism - monoaminooxidase A (MAO-A). Seven groups (from 5-HT1 to 5-HT7) and several tens of serotonin receptor subtypes have been classified by International Union of Basic and Clinical Pharmacology Committee on Receptor Nomenclature and Drug Classification on the basis of their structural and signaling features. Except 5-HT3 receptor which is coupled with ion channels and is exclusively expressed in neural components, all 5-HT receptors are G-protein-coupled type. Human and / or rodents esophagus express the following functional serotonin receptors 5-HT1-, 5-HT2-, 5-HT3- and 5-HT4-receptors. ${ }^{3}$

Despite the hard work done by researchers on the serotonin receptors in the esophagus, the mechanisms of a large doses serotonin regulation of the esophagus are not fully understood, which was the purpose of this study.

\section{Aim}

To investigate mechanisms of a large doses serotonin regulation of motor function of esophagus.

\section{Subjects and methods}

Animal experiments: The experiments were performed on 16 Wistar female rats of 5-6 months old and weigh 220-230 g. The control group consisted of 5 animals. All experiments were carried out in sparing conditions, in accordance with the 22 September 2010 the EU Directive 2010/63/EU on the protection of animals used for 
scientific purposes, national ethical guidelines and were approved by the Institutional Animal Use and Care Committee of the Moscow Clinical Research Center.

Surgery: After anesthesia the animals were fixed on the operation table, with fur on the neck and anterior abdominal wall removed, and upper-medial laparotomy was performed. In the operating wound, the distal part of esophagus was pulled away and cardiac section of the stomach was isolated. During the experiment, through the catheter, $0.9 \% \mathrm{NaCl}$, solution of serotonin and antagonists of serotonin receptors were introduced. The volume of single injection did not exceed $0.25 \mathrm{ml}$, which corresponded to the ventricular systolic volume of the rats. Infusion of drugs was performed for 10-15 s, which corresponded to 60-80 contraction of the heart of animals. These parameters of injection decreased the risk of damages to semilunar valves and disturbances of hemodynamics, connected with volume load, providing the delivery of drugs to the region of aortic arch. Then, the wound of anterior abdominal wall was covered with occlusive covering for conservation of tissues in natural functional condition. $45 \mathrm{~min}$ after the closure of wound of abdominal wall, investigation of motor function of esophagus was conducted.

The duration of experiments constituted from 2 to 9 hours. During the time of experiments, heat of animals was conducted to prevent of hypothermia. For the maintenance of activity of cardiovascular system, intravenous drip introduction of Ringer Locke solution, rheopolyglucin and lasex were used.

Drugs: To assess the relative contribution of a large doses of 5-HT to the esophagus contraction, as well as to evaluate its receptor' mechanism, serotonin, inhibitors of 5-HT1-, 5-HT2-, 5-HT3- and 5-HT4-receptors were administered into the esophageal smooth muscles. Serotonin-adipinate was introduced in dose of $500 \mathrm{mkg} / \mathrm{kg}$ intravenously.

Inhibitors of serotonin receptors used: Mianserin is the antagonist of 5HT2A, 5HT2c, 5HT3, 5HT6, 5HT7, a1-adrenoreceptors, and a2-adrenoreceptors, and it also acts as inhibitor of noradrenaline reuptake. Dosage was $1 \mathrm{mg} / \mathrm{kg}$.

NAS-181 is the strong selective blocker of 5-HTlB-receptors. Dosage was $0.1 \mathrm{mg} / \mathrm{kg}$.

SB 204741 is the. strong selective blocker of 5-HT2B-receptors. Dosage was 0.05 and $0.1 \mathrm{mg} / \mathrm{kg}$.

MDL 72222 is the 5-HT3-receptors blocker. Dosage was $0.1 \mathrm{mg}$ $\mathrm{kg}$.

RS 39604 hydrochloride is strong and selective 5HT4-antagonist, dosage was $0.1 \mathrm{mg} / \mathrm{kg}$.

Introduction of the listed inhibitors and serotonin was performed intravenously with the use of control injection of analogic amount of physiological solution, which was injected for 2-3 minutes prior to the injection of drugs. Not in any of the cases, introduction of solution changed the amplitude-frequency indicators of slow waves and spike activity.

Experiments were conducted according to the following scheme.

Trial introduction of serotonin and assessment of its influence on smooth muscles.

Blockade of 5-HT4 receptors with the subsequent investigation of the influence of serotonin.
Blockade of 5-HT3 receptors with the subsequent introduction of serotonin.

Administration of the inhibitor of 5-HT2 receptors and trial administration of serotonin.

Inhibition of 5HT1 receptors and administration of serotonin for the control of its action. After the introduction of every subsequent blocker, 40-60 $\mathrm{min}$ is passed until the end of action of the previous blocker.

Measurements of the esophagus electromyogram (EMG). Noninvasive electrodes were overlaid on the adventitia of the smooth muscles of distal part of esophagus for the registration of EMG. The esophagus EMG was measured using bipolar silver electrodes (inter electrode distance $1.5 \mathrm{~mm}$, surface $0.5-0.6 \mathrm{~mm}^{2}$ ) for the extracellular recordings. The electromyogram recording was performed with a 21-channel electroencephalograph (Neurofax EEG 4400 series, Nihon Kohden, Tokyo, Japan), the amplitude and frequency of slow electrical waves and spikes were recorded. ${ }^{4,5}$

Statistical analysis with programme Statistica-12 was done. Data are expressed as the mean \pm standard error. Student's t test was used for statistical comparisons where appropriate, and differences were considered significant at $\mathrm{p}<0.05$.

\section{Results}

Serotonin administration in the dose $500 \mathrm{mkg} / \mathrm{kg}$ led to the increase of frequency-amplitude characteristics of slow waves of the esophagus: frequency was increased from $6.3 \pm 0.2$ to $8.0 \pm 0.3 / \mathrm{min}$ $(26.9 \%, \mathrm{p}<0.05)$, amplitude - from $0.055 \pm 0.003$ to $0.55 \pm 0.004 \mathrm{mV}$ $(900 \%, \mathrm{p}<0.01)$; spices frequency was unchanged from $2.0 \pm 0.1$ to $2.0 \pm 0.2 / \mathrm{min}$ ( $\mathrm{p}>0.1$ ), amplitude - from $0.08 \pm 0.002$ to $0.075 \pm 0.0015$ $\mathrm{mV}(6,2 \% \mathrm{p}>0.05)$. That is, serotonin in massive dosage exerts a stimulatory influence on the slow wave activity of smooth muscles of the esophagus.

Blockade of 5-HT4 receptors leads to the reduction of slow wave activity of esophagus: frequencies from $6.3 \pm 0.2$ to $6.0 \pm 0.12$ / $\min (4.7 \%, \mathrm{p}>0.05)$, amplitude - from $0.055 \pm 0.003$ to $0.55 \pm 0.0025$ $\mathrm{mV}(900 \%, \mathrm{p}>0.05)$, frequency of spikes was changed from $2.0 \pm 0.1$ to $1.0 \pm 0.05 / \mathrm{min}$ (decreased on $50 \% \mathrm{p}<0.05$ ), amplitude from $0.08 \pm 0.002$ to $0.05 \pm 0.001 \mathrm{mV}$ (decreased on $37.5 \% \mathrm{p}<0.05$ ). Administration of large dose serotonin on the background of action of inhibitors of 5-HT4 receptors increased the frequency-amplitude characteristic of slow wave EMG: frequency from $6.0 \pm 0.12$ to $7.9 \pm 0.2$ $/ \mathrm{min}(31.6 \%, \mathrm{p}<0.05)$, amplitude from $0.05 \pm 0.0025$ to $0.1 \pm 0.008 \mathrm{mV}$ $(99.9 \%, \mathrm{p}<0.05)$, frequency of spikes was changed from $1.0 \pm 0.05$ to $1.0 \pm 0.06 / \mathrm{min}(\mathrm{p}>0.1)$, amplitude - from $0.05 \pm 0.001$ to $0.05 \pm 0.002$ $\mathrm{mV}(\mathrm{p}>0.1)$. Thus, inhibition of 5-HT4 receptors promoted contractile activity of the esophagus.

Administration of inhibitor of 5-HT3 receptors is accompanied by an insignificant change of slow waves EMG: frequency from $6.0 \pm 0.12$ to $7.3 \pm 0.15 / \mathrm{min}(21.7 \% \mathrm{p}<0.05)$, amplitude - from $0.05 \pm 0.001$ to $0.5 \pm 0.002 \mathrm{mV}(\mathrm{p}<0.01)$, spikes activity not appeared. Ingestion of large dose serotonin on the background of action of 5-HT3 receptor blockers is accompanied by the increase of frequency-amplitude parameters of slow wave EMG: frequency from $7.3 \pm 0.15$ to $7.5 \pm 0.14$ $/ \mathrm{min}(2.7 \%, \mathrm{p}>0.1)$, amplitude from $0.05 \pm 0.001$ to $0.05 \pm 0.003 \mathrm{mV}$ $(\mathrm{p}>0.1)$. That is, blockade of 5-HT3 receptors almost completely prevent the stimulatory effect of a large doses of serotonin, that 
indicate the localization of 5-HT3,4 receptors on the membrane of efferent intramural neurons.

Inhibition of 5-HT2 receptors increased frequency of slow wave EMG from $7.3 \pm 0.15$ to $11.0 \pm 0.3 / \mathrm{min}(50.6 \%, \mathrm{p}<0.05)$, amplitude from $0.05 \pm 0.001$ to $0.18 \pm 0.007(260 \% \mathrm{p}<0.01)$. Introduction of large dose serotonin on the background of inhibition of 5-HT2 receptors lead to a decrease of EMG frequency from $11.0 \pm 0.3$ to $7.6 \pm 0.2 / \mathrm{min}$ $(-30,9 \%, \mathrm{p}<0.05)$, amplitude - from $0.18 \pm 0.07$ to $0.20 \pm 0.009 \mathrm{mV}$ $(11,1 \% \mathrm{p}<0.05)$. I.e. blockade of 5-HT2 receptors completely turns off the investigated effect - increase of motor function of esophagus with introduction of serotonin.

Deactivation of 5-HT1 receptors of serotonin decreases the frequency of slow wave EMG from $11.0 \pm 0.3$ to $6.5 \pm 0.18 / \mathrm{min}(40 \%$, $\mathrm{p}>0.05$ ), amplitude is remained unchanged. Administration large dose serotonin on the background of inhibition of 5-HT1 receptors almost excluded the investigated phenomenon: frequency of the slow wave EMG is slightly increased from $6.5 \pm 0.18$ to $6.7 \pm 0.18 / \mathrm{min}(3.1 \%$, $\mathrm{p}>0.1$ ), amplitude was remained unchanged. Blockade of 5HT1 receptors completely excludes the investigated effect. Given the complete exclusion of the investigated phenomenon with blockade of 5-HT2 and 5-HT1 receptors, we believe that 5-HT1 and 5-HT2 receptors are receptors of effector tissues.

\section{Discussion}

In the regulation of motor activity of the esophagus involved the central nervous system and a number of hormones, neurotransmitters, among the latter a significant role is assigned to serotonin and its receptory apparatus. ${ }^{6,7}$ It is known that an elevated serotonin level accompanies gastroesophageal reflux. ${ }^{8}$

Serotonin has a stimulatory effect on the motor function of the esophagus. Activation of serotonin receptors can be performed by various doses of the neurotransmitter. ${ }^{2}$ As we showed earlier, small and medium doses of serotonin, and, in this study, also large doses of serotonin have a stimulatory effect on the neurons of the intermuscular plexus by activating 5-HT3.4 receptors and on effector (smooth muscle cells) by activating 5-HT1, 2 receptors. Blockade of 5-HT3,4 receptors does not completely turn off the effect of large doses of serotonin due to the reverse capture of the excess of the neurotransmitter. In a number of pathologies of the upper parts of the digestive tract, both increased (gastroesophageal reflux) and decreased serotonin level can be observed. Thus, an inverse correlation between the level of serotonin and the total duration of gastroesophageal reflux $(\rho=-0.380, p=0.002)$ was revealed in all groups of patients, regardless of the clinical form of the disease. ${ }^{9}$

Hence the importance of study the dose-dependent effects of serotonin in the esophagus. Given that 5-HT3.4-receptor blockers do not completely disable the effect of large doses of serotonin, we believe that these receptors are ganglionic, and excess serotonin interacts either with presynaptic receptors or with effector 5-HT1.2 receptors

\section{Conclusion}

We conclude that the regulation of esophageal smooth muscles by a large doses of serotonin involves receptors of ganglionic serotoninergic neurons, which expressed 5-HT3,4 receptors transmitting excitation to $5-\mathrm{HT}_{1,2}$ receptors. Activation of these receptors contributes to serotonin stimulation of EMG of the esophageal smooth muscles.

\section{Acknowledgments}

None.

\section{Conflicts of interest}

The authors declare no conflict of any kind.

\section{References}

1. Mittal RK. Motor Function of the Pharynx, Esophagus, and its Sphincters. San Rafael (CA): Morgan \& Claypool Life Sciences; 2011.

2. Lychkova AE, Golubev Yu Yu, Puzikov AM. Serotonin Receptors Mediate Contractile Activity of Rat's Esophagus in vivo. Arch Organ Transplant. 2017;2(1):19-22.

3. International Union of Basic and Clinical Pharmacology Committee on Receptor Nomenclature and Drug Classification Electronic resource IUPHAR/BPS Guide to pharmacology, 2014

4. Lychkova AE. Coordination of myoelectrical activity of the small and large intestine. Exper clin gastroenterol. 2012;2(3):59-61.

5. Lychkova AE, Puzikov AM. Electrical activity of the digestive tract and its enteral correction. Exper clin gastroenterol 2015;120(8):25-29(Russian).

6. Osadchuk MA, Osadchuk AM, Balashov DM, et al. Clinical features of gastroesophageal reflux disease: clinical, endoscopic and morphofunctional features Medical almanac. 2011;2:53-58(Russian).

7. Lychkova AE. Nervous regulation of motor activity of the esophagus. Exper clin Gastroenterol. 2013;6:52-56(Russian).

8. Yang L, Cai H, Tou J, et al. The role of the 5-hydroxytryptamine pathway in reflux-induced esophageal mucosal injury in rats. World $J$ Surg Oncol. 2012;10:219

9. Bystrova DA, Grishechkina IA, Trukhha DI, et al. Interrelation of serotonin and parameters of the psychological profile of the personality in patients with gastroesophageal reflux disease. Diary Kazan Med School. 2014;1:16-19 (Russian). 